IZA DP No. 10119

Migration Experience and Access to a First Job in Uganda

Delphine Boutin

August 2016

Forschungsinstitut zur Zukunft der Arbeit Institute for the Study of Labor 


\title{
Migration Experience and Access to a First Job in Uganda
}

\author{
Delphine Boutin \\ CERDI, University of Auvergne \\ and IZA
}
Discussion Paper No. 10119
August 2016

\author{
IZA \\ P.O. Box 7240 \\ 53072 Bonn \\ Germany \\ Phone: +49-228-3894-0 \\ Fax: +49-228-3894-180 \\ E-mail: iza@iza.org
}

\begin{abstract}
Any opinions expressed here are those of the author(s) and not those of IZA. Research published in this series may include views on policy, but the institute itself takes no institutional policy positions. The IZA research network is committed to the IZA Guiding Principles of Research Integrity.

The Institute for the Study of Labor (IZA) in Bonn is a local and virtual international research center and a place of communication between science, politics and business. IZA is an independent nonprofit organization supported by Deutsche Post Foundation. The center is associated with the University of Bonn and offers a stimulating research environment through its international network, workshops and conferences, data service, project support, research visits and doctoral program. IZA engages in (i) original and internationally competitive research in all fields of labor economics, (ii) development of policy concepts, and (iii) dissemination of research results and concepts to the interested public.
\end{abstract}

IZA Discussion Papers often represent preliminary work and are circulated to encourage discussion. Citation of such a paper should account for its provisional character. A revised version may be available directly from the author. 


\section{ABSTRACT}

\section{Migration Experience and Access to a First Job in Uganda*}

Does experiencing internal migration hasten the access to the labour market? This paper provides an answer by studying the gap in transition length to a first job between young people in Uganda that have ever migrated inside the country and never-migrants of the same age category. To take into the account the specific context of Uganda (some enters at a very young age, other before the end of school and other have never attended school), different starting points of transition are considered: from the date of birth, from the minimum legal age (14 years old) and from the date of school exit. Extended proportional hazards models shows that transition duration is shorter for migrants than for non-migrants (except for the school-towork transition), although effects vary considerably according to the area of origin and destination and the reasons for migration. Decomposition in durations' gap reveals the importance of unobservable factors, especially the role of area of origin, gender, age cohort and access to education.

JEL Classification: J15, J61, J64

Keywords: internal migration, school-to-work transition, job search, youth employment

Corresponding author:

Delphine Boutin

CERDI

65 Boulevard F. Mitterrand

Boite Postale 320

63009 Clermont-Ferrand CEDEX 1

France

E-mail: delphine.boutin@udamail.fr

\footnotetext{
* This paper has been prepared for the ILO W4Y Symposium - Labour Market Transitions of Young Women and Men. I would like to express my gratitude to Sara Elder and the participants of the Work4Youth Global Research Symposium held in Geneva in March 2016 for their valuable comments and suggestions.
} 


\section{Introduction}

Migrating to new places for better job prospects and higher wages is a widely used strategy among youth in developing countries. In economic literature, issues regarding the labour market outcomes of migrants from a developing country have been almost exclusively linked to international migrants located in Western countries. ${ }^{1}$ Internal migration within developing countries has received less attention, which is striking as it is a far more common phenomenon with potentially large consequences for local labour markets, and for poverty levels in general (De Brauw et al., 2014; McMillan \& Harttgen, 2014).

Internal migration is generally conceptualized as a human capital investment: individuals (and their households) maximize their welfare by comparing the current costs of migration to its expected returns. Rural to urban migration are often motivated by the prospect of higher wages (Todaro, 1969; Harris \& Todaro, 1970) and the expectation of better employment transitions (Fields, 1975). Empirical evidence of the internal migrants' performance in the labour market (in respect to their resident's counterpart) is however scarce. ${ }^{2}$ Despite its potential interest for policy makers, migrants are generally excluded from the analysis because their peculiar performances in the labour market can be attributed to differentials in pre-migration endowments such as age, work experience, education and psychology (Adsera \& Chiswick, 2006). The aim of this study is to assess if the internal migration experience is an impediment or a driver for accessing a first job, or if, in other terms, internal migrants successfully integrate into the labour market. The primary variable assessed is the transition length to a first job, as it represents a better proxy of the ease or difficulties a young may face and the complexity of labour market access than the static information conveyed by the unemployment rate or occupational status of an individual. A longer entry duration may be associated with social and psychological problems, the degradation of an individual's human capital and/or a signal toward employers of a low level of productivity, making the individual even less "employable" as time passes. As past experiences of unemployment may lead to more unstable and lower paid jobs, the transition length could also be a good predictor of future labour market performance (and even future "life" outcomes such as marriage or parenting).

In fact, we do not know if migrants will have shorter or longer durations to a first job. Migrants might be expected to experience longer durations if skills acquired in their region of origin are not perfectly transferable in the destination market, or if they face some forms of discrimination due to asymmetries of information or pure taste-based prejudices. ${ }^{3}$ However, migrants might also maintain specific characteristics that are favoured in the destination markets, such as a lower propensity to risk-aversion (Katz \& Stark, 1986; Bonin et al., 2009) or some financial resources (Borjas, 1987). The latter can determine whether or not a young migrant can support him/herself through a lengthy period to first job or whether they will need to take up whatever job that comes around regardless of quality in order to earn an income. Another specific characteristic linked to

\footnotetext{
${ }^{1}$ For recent reviews, see Dustmann et al. (2008) and Kerr \& Kerr (2011).

${ }^{2}$ The closest contextual study of this paper found is one done by Thomas (2008), although it but has focuses on international and highly educated return migrants in Uganda.

${ }^{3}$ Yang \& Guo (1996) found, for example, that Chinese rural-to-urban migrants tended to work in marginal jobs that local residents did not want to do. A differential treatment in terms of wage and welfare benefits is also frequently observed worldwide among migrants and ethnic minorities.
} 
both the migration decision and the probability to find a job is the quality and quantity of networks.

While this study can have relevant implications to many developing countries, it focuses solely on Uganda as a first examination of the methodology. This country has experienced substantial internal migration. The 20-years ethnic war in Northern Ugandan has resulted in some North-South migration (IOM, 2015). Voluntary international (628.000 individuals in 2013, (UBOS, 2012)) and internal migration ( 1.3 million according to the 2002 census) is also common. The last decade has seen a massive migration from rural towards urban areas or towards rural regions with high economic activities (tea and sugar plantations). The high population growth (3.2\% per annum) and the extend of underemployment are the main drivers of this labour migration. ${ }^{4}$. The demographic pressure affects particularly young people (below 30 years old), which count for $78 \%$ of the total population, of which half are less than 15 years old (UBOS, 2012). However, as commonly observed, young people register a higher unemployment rate than older age groups (ILO,2015). While youth unemployment is low in comparison to other regions, it is offset by conditions of working poverty and widespread vulnerable employment (Musonda, 2006). What is interesting in this study is that the timing and the length of access to a first job vary considerably across regions according to the socio-economic contexts of the countries and the individual characteristics of the youth (among which are education level, sex and household income level). In Uganda, where more than 53 tribes cohabitate, it would be expected that the ethnicity of youth will also result in differing results in the labour market transition (Ssennono et al., 2008).

This paper takes advantage of the comprehensive school-to-work transition surveys (SWTS) implemented by the ILO-Work4Youth programme, ${ }^{5}$ in order to compare labour market outcomes of Ugandan migrants and residents at destination areas. I focus on young people (aged 15 to 29 years old), as this category is the one most likely to migrate and to begin their labour market transitions. In short, the examination of how internal migration impacts the transition to first job in Uganda consists of the following two steps. First, I calculate the length of access to a first job, whatever its characteristics. Three types of transition are considered: the first one is unconditional in the sense that the starting point is the date of birth, allowing people to start working while being a child. The second transition takes 14 years old (the Ugandan legal minimum working age) as a starting point, conditionally on never having worked before that age, i.e. on never have been child labourers. The third one is a standard school-to-work transition, from date of school exit to date of a first job, conditionally on having ever attended school. Duration analysis are used to calculate these transitions lengths. The second step decomposes these estimated transition lengths into an explained and unexplained part. In this step, the main difficulty lies in adapting an Oaxaca-Blinder-style decomposition to non-linear models.

Simple comparison and Kaplan-Meier estimations first shows that the transition for accessing

\footnotetext{
${ }^{4}$ Others pushing factors explain these population movements: internal migration is also driven by marriage purpose, especially in rural zones and for girls (IOM, 2015; Kudo, 2015). Beegle \& Poulin (2013) highlight the fact that migration is linked to the transition to adulthood or an attempt to diversify income source (Christiaensen et al., 2013; Rosenzweig \& Stark, 1989).

${ }^{5}$ The Work4Youth Project is a five-year partnership between the ILO and The MasterCard Foundation that aims to promote decent work opportunities for young men and women through knowledge and action.
} 
to a first job takes more time for migrants than for non-migrants. However, when controlling for relevant covariates (through Cox proportional hazard models), the reverse is observed: migrants enter in the labour market at an early age (compared to non-migrants) when the possibility for entering while still being a child is taken into consideration (Transition 1). No significant differences is noted when focusing on never-child labourers (Transition 2) or on the school-to-work transition (Transition 3). Findings also highlight heterogeneous effects according to the type of migrant (area of origin and destination), and the reasons for migration (economic, marriage, family), while no gender difference is observed. Decomposition highlights that most of the gap in mean duration for the first and third transitions is attributable to differences in unobservable component regarding the area of origin, the gender and the age cohort. Observable differences in education level and age cohort are the main factors that widen the gap in transition between migrants and non-migrants.

The remainder of the paper is organized as follows: section 2 reviews the literature related to the access to employment for internal migrants. Section 3 introduces the dataset and specific descriptive statistics. Section 4 operates a simple comparison of the transition lengths between migrants and non-migrants, and section 5 refines the analysis by incorporating relevant covariates correlated with transitions durations and decomposing them into an explained and unexplained part. Finally, section 6 concludes.

\section{Internal migration and access to employment}

As stated above, economic theory is ambiguous in predicting whether or not migrants would have easier access to the labour market at their place of destination in comparison to local residents. This section expands on some of the mechanisms between migration and labour market outcomes introduced in the previous section.

Human capital models of international migration highlight that migrants are positively selected compared to the home population. Borjas (1987) explains the migration decision models by applying a Roy (1951) model of self-selection to international migration. In his model, rational individuals choose the optimal market to participate in between several destinations depending on their comparative advantages on both their observed and unobserved characteristics. Hence, individuals are all potential migrants self-selecting the job and the location that gives them the highest expected earnings or the highest return to their skills. The internal migration decision falls under identical mechanisms than for the international one, only the destination differs (Todaro, 1969; Harris \& Todaro, 1970; Fields, 1975).

Besides non-favourable economic situations and income-maximization strategies, selection into migration is also driven by specific psychological traits (such as personality, non-cognitive skills, risk aversion, locus of control, a stronger willingness to find an employ, etc.) that may have an influence on labour market outcomes (Chiswick, 1999). Recently, the literature has pointed out the specific role of informal information networks, such as family, friends and local diaspora, for reducing the searching and informational costs and enabling a successful integration into the labour market. In the specific case of Uganda, around $70 \%$ of migrants (against $61 \%$ of residents) have 
found their current job trough friends or family. The use of both formal and informal job-search channels increases the chance to find a job. ${ }^{6}$ In the same vein, access to employment is facilitated by marriage with a resident. Basu (2015) argues that a native spouse may also help reduce the information costs regarding local job markets and may increase the likelihood of employment.

Beyond the self-selection of migrants on specific (observable or not) characteristics, a differential in job access between migrants and non-migrants could also be related to the background of immigrants and their reasons for migration. Refugees from war are a specific but common population of migrants in Uganda for which the above-mentioned schemes is inappropriate. For this minority group, opportunities and labour market access in areas of destination might be depressed by the traumatic experience resulting in poor health (and trauma) or by a lack of appropriate skills. Migration among youth is another particular type of migration, as it can reflect movements through the life stages from adolescence toward adulthood, thus possibly covering periods of schooling, first employment and/or marriage and family formation. In the case of Uganda based on the 2015 SWTS, young people left their place of original residence in search of employment prospects (38\% of young migrated male and $18 \%$ of females) or for educational purposes (15\% of males and $8 \%$ of females). But a non-negligible part of youth migration is "forced" and therefore does not result in a trade-off between costs and opportunity. Nearly one-third of male migrants (32\%) and $19 \%$ of female migrants reported having moved because the family moved, thus presumably not self-determined. Then a very large share of young women (47\%) but on $1 \%$ of young men moved as a result of marriage. In a more general way, the human capital of migrants (type and level of education, qualifications and abilities) needed to access a first employment may be inappropriate in the region of destination (Chiswick, 1978; Borjas, 1985), or of lower quality. ${ }^{7}$ The transferability of a migrant's human capital also depends of the reason for migration; higher skills transferability is observed among economic migrants (Chiswick \& Miller, 2012).

Other kind of frictions may arise when resident employers face informational deficits in assessing the migrant's skills and potential productivity. The uncertainty about the migrant's productivity creates incentives for employers to use observable (but discriminating) characteristics (ethnicity, gender, age, height) as a proxy for productivity (Arrow et al., 1973; Phelps, 1972; Cain et al., 1986; Clark \& Drinkwater, 2008). The resulting discrimination is often not based on any purposive prejudice but rather on a rational response to information gaps. Still, we cannot exclude entirely some taste-based discrimination, leading to a desire from employers to avoid specific groups (Becker, 1962). In such cases, employers under-weigh migrant's productivity respective to non-migrants, adding difficulties in the migrant's search for employment.

While discrimination towards migrants could induce longer transitions length for them, two

\footnotetext{
${ }^{6}$ However, job-related networks are often clustered in one (or in better cases a few) occupations, potentially leading to a mismatch between the occupations in which the young has contacts and level of skills. The quality and job satisfaction is likely to be lowered when the job is obtained thanks to informal network (Bentolila et al., 2010).

${ }^{7}$ Schooling in rural areas is typically poorly funded, delivered in overcrowded classrooms, and associated with lesser outcomes in reading and mathematics literacy relative to what is reported for equivalent levels of education in urban areas. In Uganda, the 20-years conflict war localized in the Northern region created persistent geographical inequalities in terms of health and education.
} 
counterbalancing factors could accelerate the access to a first job: the job match model of Pissarides (2000) assumes that the job matching rate (the rate for which people expect to find a new job) depends on the total number of vacant jobs in the labour market and is inversely correlated with the searching cost. In a context of job stratification, if migrants are more likely to accept any type of jobs (while local residents do not), then migrants have a higher overall job matching rates (Knight \& Yueh, 2004). Moreover, taking longer in the job search for a suitable job, i.e. the concept of luxury unemployment, implies the jobseeker has a support structure. In the absence of unemployment insurance, migrants lacking familial support might not be able to afford a period of long job search and would thus tend to accept the first offer that comes regardless of working condition or the match with his skills or level of education (Udall \& Sinclair, 1982). ${ }^{8}$

\section{Stylized facts about youth labour market in Uganda}

\subsection{Dataset and sample restriction}

Studies on flows within labour markets are relatively scarce, often due to a lack of appropriate information. The available surveys often miss the ability to capture labour mobility and rather focus on the current state in the labour market. The ILO SWTS, implemented in 34 countries through the Work4Youth partnership between the ILO and The MasterCard Foundation, aimed to overcome the lack of flow data by including a section dedicated to capturing the historical perspective of the young respondent's history of economic activities. In the case of Uganda, the SWTS was implemented twice by the Ugandan Bureau of Statistics (UBOS) first in 2013 and again in 2015. This paper is based on the 2015 survey, with a sample of 3,049 youth. ${ }^{9}$

For the purpose of the study, some restrictions in the sample were made. First, individuals that declared having worked before the age of 5 (24 observations) were dropped as a presumed measurement error. Next, foreign migrants ( 5 more observations) were also dropped as the focus of the paper is on internal migrants. Finally, as this paper focuses on transitions, observations with no information on the date of starting employment or ending school were also deleted. In all, the total sample examined in this exercise came to 3,009 Ugandan youth aged 15â29.

\subsection{Main variables definition}

Non-migrant young people refers to individuals that have never lived outside the administrative area in which they were surveyed. In contrast, (internal) migrant youth are defined as those who had lived in another administrative area. ${ }^{10}$ According to this definition, $17 \%$ of young Ugandans are migrants (Table 1). The rural-to-urban migration accounts for only $23 \%$ of the total, while rural-to-rural migration represents $46 \%$. Urban youth also migrated, either to another urban area

\footnotetext{
${ }^{8}$ In Africa, the system of extended families ensures a certain form of solidarity but also leads to a number of reciprocal obligations on a wider scale.

${ }^{9}$ Micro data files for 53 surveys in 34 countries are available on the W4Y website.

${ }^{10}$ For the remainder of the report, the term migrant youth will be used without the reminder that we refer only to internal migrants.
} 
$(17 \%)$ or even to rural areas $(15 \%)$.

Table 1: Characteristics of young migrants in Uganda

\begin{tabular}{llll}
\hline & Women & Men & Total \\
\hline \hline Non-migrant & 78.1 & 88.9 & 83.1 \\
Migrant & 21.9 & 11.1 & 17.0
\end{tabular}

\begin{tabular}{llll} 
Migration flows & & & \\
\hline Urban to urban & 16.7 & 16.8 & 16.7 \\
Rural to urban & 22.5 & 22.8 & 22.6 \\
Rural to rural & 48.7 & 38.3 & 45.6 \\
Urban to rural & 12.1 & 22.2 & 15.1
\end{tabular}

\begin{tabular}{llll} 
Migration reasons & & & \\
\hline Economic migrants & 23.2 & 50.0 & 31.2 \\
Marriage migrants & 48.6 & 0.7 & 34.3 \\
Others migrants & 28.2 & 49.3 & 34.5 \\
\hline
\end{tabular}

Unfortunately, data are not informative on the previous migration experience, or on the date at arrival in the area. I am thus not able to distinguish between recently arrived migrants and long-term migrants that arrived in their childhood following a decision within the household and for which assimilation and integration are likely to be easier. It is also not possible to distinguish between temporary migrants (those who left their administrative areas at one time but came back) from migrants remaining at their non-original destination. ${ }^{11}$ One solution is to define different types of migrants according to their reasons from migration. Economic migrants refer to migrants that have come in the surveyed administrative areas for work or educational purpose. I assume that these migrants came at an older age than other migrants. Economic migrants concern $50 \%$ of male migrants and $23 \%$ of female migrants, and are mainly located in urban areas. Marriage migrants concerns mainly women (49\% of them) and rural-to-rural migration, while others migrants are principally young people that migrated with their family, potentially at an early age. As a robustness checks, regressions are re-performed by interacting the type and the gender of migrants.

Several transitions are estimated to take into account all possible educational and employment scenario in Uganda. In this country, as in many developing countries, the standard school-to-work transitions is of a low interest as a non-negligible proportion of youth have never attended school

\footnotetext{
${ }^{11}$ Theoretically, returnees are often viewed as "unsuccessfully" migrants, who did not succeed in finding a formal job in urban area (Harris \& Todaro, 1970). But it could also be understood as a successful migration experience if the aims of it was to reach a specific objective or a "saving target" (Cassarino, 2004; De Vreyer et al., 2010; Démurger \& Xu, 2011; Marchetta, 2012). In the context of Uganda, the 20-years conflict has resulted in the internal displacement of $6 \%$ of the total population. By 2011, the vast majority of them has returned home.(UNHCR, 2011)
} 
(5\%) or have start working before the end of their education (40\%). ${ }^{12}$ All transitions studied have the same end point: the date of access to a first job (month and year), based on responses to the history of economic activities included in the questionnaire. However, the starting point and the conditions associated differ. Three methods of duration calculations are considered: the first one is unconditional, with the starting point as the date of birth, thus allowing that some people started working as children (condition 1). The second method takes a starting point of 14 years (the Ugandan legal minimum working age) conditionally on never having worked before that age, i.e. on never having been a child labourer (condition 2). The third method uses a standard school-to-work transition, from date of school exit to start date of a first job, conditionally on having ever attended school and never having combined work with schooling (condition 3). ${ }^{13}$ Duration analyses are used to calculate these transitions lengths.

\subsection{Descriptive statistics}

Characteristics presented in Table 2 suggest that migrants are a quite specific population, different in observables from the non-migrant population. Migrants are thus slightly older, with a higher education level, and live primarily in urban area. The higher proportion of young women among migrants is explained by marriage-driven mobility. Young women are more often married and with children than young men with a higher propensity to have children. ${ }^{14}$ Regarding the educational background, there is no statistical difference between migrants and non-migrants on the probability to have once attended school. However, the education level is much higher for migrants. Note that this difference is mainly driven by economic migrants, which are three times more present in higher level of education (university) than non-migrants. In contrast, migrants for marriage reasons presents almost the same educational characteristics than non-migrants (statistics not shown). The decomposition into type of migration reveals that rural-to-rural migrants are lesser educated respective to other migrants.

These differences in characteristics (in favour of migrants from a labour market perspective) could explain why labour market outcomes are better for migrants than for non-migrants. At the time of the survey, $73 \%$ of young migrants was employed versus $65 \%$ of non-migrants of the same age. While the proportion of youth that started working before the age of 15 (child labourers) is not significantly different between the two groups, $82 \%$ of migrants had already had at least one experience in the labour market against $72 \%$ of non-migrants. Migrants tended also to be less often inactive at the time of the survey. The proportion of young people ever employed in the formal sector is low for both migrants and non-migrants (less than $5 \%$ have ever been in formal employment).

\footnotetext{
${ }^{12}$ See also the two published reports summarizing results of the two rounds of SWTS in Uganda: Byamugisha et al. (2014) and UBOS (2016).

${ }^{13}$ In this way, we cannot observe negative transitions.

${ }^{14}$ Nearly half $(48.5 \%)$ of young women were married in 2015 compared to $28.3 \%$ of young men (UBOS, 2016).
} 
Table 2: Selection bias on unobservable characteristics - all sample

\begin{tabular}{|c|c|c|c|c|c|c|c|c|c|}
\hline & \multicolumn{3}{|c|}{ Non-migrants } & \multicolumn{3}{|c|}{ Migrants } & \multirow{2}{*}{ Diff in mean } & \multirow{2}{*}{ T-stat } & \multirow{2}{*}{ p-value } \\
\hline & Mean & St. Dev & \# Obs & Mean & St. Dev & \# Obs & & & \\
\hline \multicolumn{10}{|c|}{ Individual characteristics } \\
\hline Male & 0.49 & 0.50 & 2499 & 0.30 & 0.46 & 510 & 0.19 & 7.92 & 0.00 \\
\hline Urban & 0.23 & 0.42 & 2499 & 0.40 & 0.49 & 510 & -0.16 & -7.75 & 0.00 \\
\hline Age & 20.79 & 4.33 & 2499 & 22.48 & 4.07 & 510 & -1.69 & -8.13 & 0.00 \\
\hline Have children & 0.39 & 0.49 & 2499 & 0.58 & 0.49 & 510 & -0.19 & -7.95 & 0.00 \\
\hline Single & 0.62 & 0.49 & 2499 & 0.39 & 0.49 & 510 & 0.23 & 9.65 & 0.00 \\
\hline \multicolumn{10}{|c|}{ Educational background } \\
\hline Ever attend & 0.94 & 0.24 & 2499 & 0.95 & 0.21 & 510 & -0.01 & -1.08 & 0.28 \\
\hline No education & 0.51 & 0.50 & 2499 & 0.35 & 0.48 & 510 & 0.15 & 6.34 & 0.00 \\
\hline Primary school & 0.29 & 0.45 & 2499 & 0.31 & 0.46 & 510 & -0.02 & -1.07 & 0.28 \\
\hline Second. school & 0.16 & 0.36 & 2499 & 0.23 & 0.42 & 510 & -0.08 & -4.23 & 0.00 \\
\hline Higher level & 0.05 & 0.22 & 2499 & 0.10 & 0.30 & 510 & -0.05 & -4.60 & 0.00 \\
\hline \multicolumn{10}{|c|}{ Labour market status } \\
\hline Employed & 0.65 & 0.48 & 2499 & 0.73 & 0.45 & 510 & -0.08 & -3.35 & 0.00 \\
\hline Unemployed & 0.05 & 0.22 & 2499 & 0.10 & 0.30 & 510 & -0.05 & -4.51 & 0.00 \\
\hline Inactive & 0.30 & 0.46 & 2499 & 0.17 & 0.38 & 510 & 0.13 & 5.93 & 0.00 \\
\hline $\begin{array}{l}\text { Ever in formal } \\
\text { empl. }\end{array}$ & 0.04 & 0.20 & 2499 & 0.05 & 0.22 & 510 & -0.01 & -0.93 & 0.35 \\
\hline Never employed & 0.28 & 0.45 & 2499 & 0.18 & 0.38 & 510 & 0.10 & 4.85 & 0.00 \\
\hline Child labourer & 0.23 & 0.42 & 2499 & 0.21 & 0.40 & 510 & 0.02 & 1.04 & 0.00 \\
\hline $\begin{array}{l}\text { Worked while } \\
\text { schooling }\end{array}$ & 0.41 & 0.49 & 1561 & 0.34 & 0.48 & 383 & 0.07 & 2.39 & 0.02 \\
\hline
\end{tabular}

\section{Comparing transition lengths}

\subsection{Simple comparison}

While they have a lower tendency to work than migrants, the non-migrants who do work had a slightly shorter transition period to the first job (Figures 1 to 6). The first graph (Figure 1) represents the average transition length to a first job, expressed in years. As the starting point is the date of birth, this transition can be interpreted as the average age of entering the job market, regardless of the education path or the legality of the employment status (recalling the 14 year legal minimum working age in Uganda). Thus, non-migrants obtained a first job at the average age of 16 years, while migrants started working at the average age of 17 . When disaggregating by characteristics such as sex, area of residence, working before/after the end of schooling, having 
entered before/after 14 years old, a significant gap remains between migrants and non-migrants (from 3 months for non-child labourers to 15 months for men). ${ }^{15}$

The second graph (Figure 2) focuses on young people that had not been employed before the age of 14 (i.e. excluding former child labourers). This graph is also expressed in years from the starting point of 14 years old. One can observe that there are no statistically significant gaps between migrants and non-migrants, whatever the youth's characteristics. In other terms, once excluded child labourers that mechanically hasten the transition to employment, there is no longer a difference in the transition durations to employment between migrants and non-migrants. The same comment holds for the calculations based on the school to work transition (Figure 3).

Figure 1: Mean transition length to a first job (in years) (condition 1)

Condition: Never been employed before 5 years old

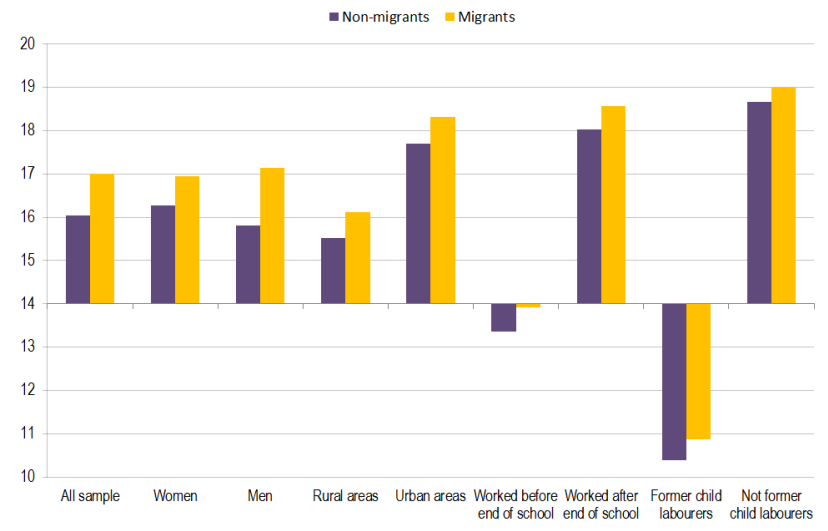

$\overline{{ }^{15} \text { Statistical differences are calculated using t-tests. }}$ 
Figure 2: Mean transition length from 14 years old to a first job (in years) (condition 2)

Condition: Never been employed before 14 years old

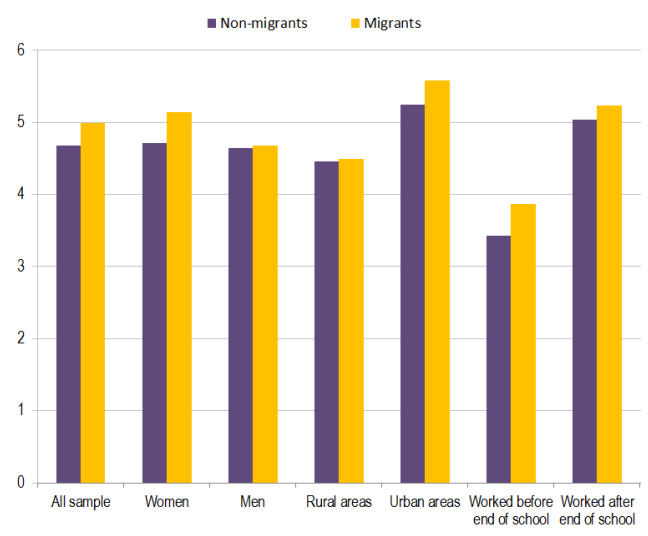

Figure 3: Mean transition length from end of school to a first job (in years) (condition 3)

Condition: Having ever attended school and not worked before end of schooling

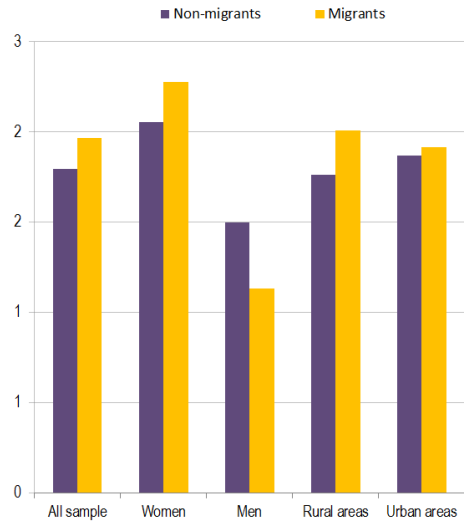

\subsection{Kaplan-Meier estimations}

Simply comparing the average transition length is biased in several ways. First, the probability of entering into the labour market is likely to vary over time and depends on the time you have already spent looking for a job. It seems plausible that the longer the never-employed state lasts, the more likely that a first job will be obtained in the next month. In some cases, a "scarring effect" could appear, inducing more difficulties for youth that spend a long period as never-employed (Arulampalam, 2001). In such cases, the longer the non-employment state persists, the less likely the state will end in the next months. In the literature, this is called the duration dependency whereby the time spent in a given "state" changes the probability of transition to another state.

The second issue that is not considered in the simple comparison is the length-biased sampling. 
Among those never-employed at a given time, the distribution of duration is biased by the presence of those who are less likely to ever leave the non-employment state (young mothers for example). The retrospective nature of the data allows us to observe completed transition for some individuals that have already had access to employment at the time of the survey. However, some young people are still never-employed (i.e. in uncompleted transition) when interviewed: the SWTS data only informs us how long an individual has been never employed, but not when/if he will ever enter into employment. The right-censored nature of the data is an issue if the distribution of incomplete durations differs from the distribution of complete durations. Not excluding these young people still not employed at the time of a survey is of particular interest in this study as the "never been employed" state reflects different storylines: some are too young to have started their transitions (including many current students), some are discouraged workers and only a portion of them are inactive non-students. A duration model is thus preferred to identify actual length of transition to a first job.

As a first step in examining and comparing transition lengths across the two groups, I calculate Kaplan-Meier (K-M) failure functions, given by:

$$
F\left(a_{K}\right)=1-\left[\Pi_{i=1}^{K}\left(\left[n_{i}-h_{i}\right] / n_{i}\right)\right]
$$

where $n_{j}$ is the number of youth still never-employed at the time of the survey and $h_{j}$ the number of those that has transited (i.e. has obtained a first job) at age a. The Kaplan-Meier non-parametric estimator enables to estimate the survival curve. The survival function $S(a)=$ $1-F(a)=\operatorname{Prob}\left(a_{i}>t\right)$ measures the proportion of individuals (the "survivors") still present in never-employment (who have survived) after a specific age. It refers to the probability for an individual that his duration in that state will be greater than age a. Failure function are more of interest in this paper as it refers to the probability of entering into the labour market before age a.

Figure 4 presents the Kaplan-Meier estimations, distinguishing between the migration status (migrants or non-migrants) and the type of migration (economic migrants, marriage migrants or family migrants). Non-migrants appear to have shorter transition paths: at every point they enter first job at an earlier age than migrants. At the legal age of 14 (red line in Figure 4), $24 \%$ of migrants and $35 \%$ of non-migrants had achieved a first job. At 20 years old, the proportions were $73 \%$ for migrants and $77 \%$ for non-migrants. The second part of Figure 4 distinguishes among the motives for migration, showing that individuals that migrate for marriage purpose have the same transitional path than non-migrants (see Log-rank test in Annex I, table A1). Economic migrants (and to a lesser extent family migrants) presents a different pattern. Results are however mainly driven by rural-to-rural migrants: as shown in Annex II, tableA2, the other types of migrations present no statistical differences in their transition paths. 
Figure 4: Kaplan-Meier failure function of transition length to a first job (condition 1)

Condition: Never been employed before 5 years old
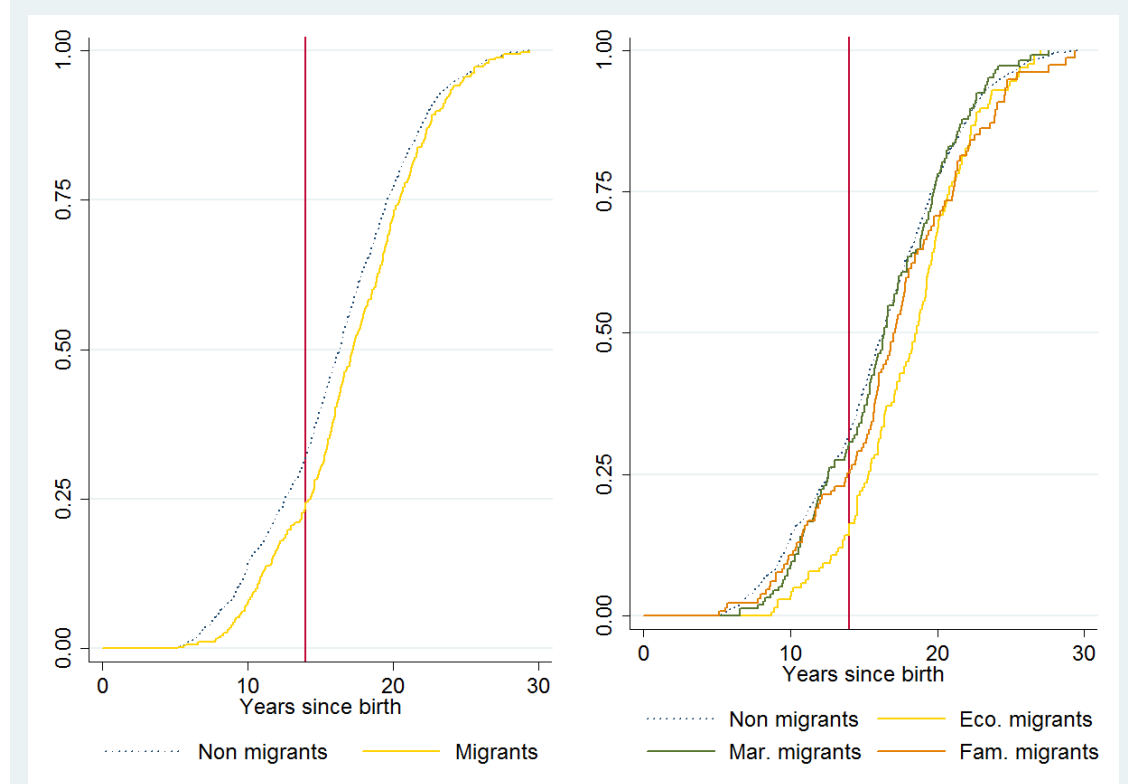

Figure 5 refers to the access to a first job from the age of 14 years, excluding former child labourers. In this case, we observe no significant differences between young migrants and non-migrants. The school-to-work transition survival function in Figure 6, however, does show some differences between migrants and non-migrants: migrants enter more slowly in a first job than non-migrants, but this difference is not significant and is mainly driven by migration for marriage reasons. ${ }^{16}$

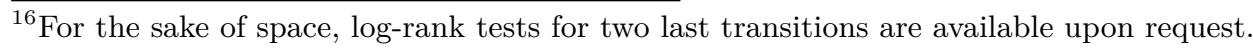


Figure 5: Kaplan-Meier failure function of transition length to a first job from 14 years old (condition 2)

Condition: Never been employed before 14 years old
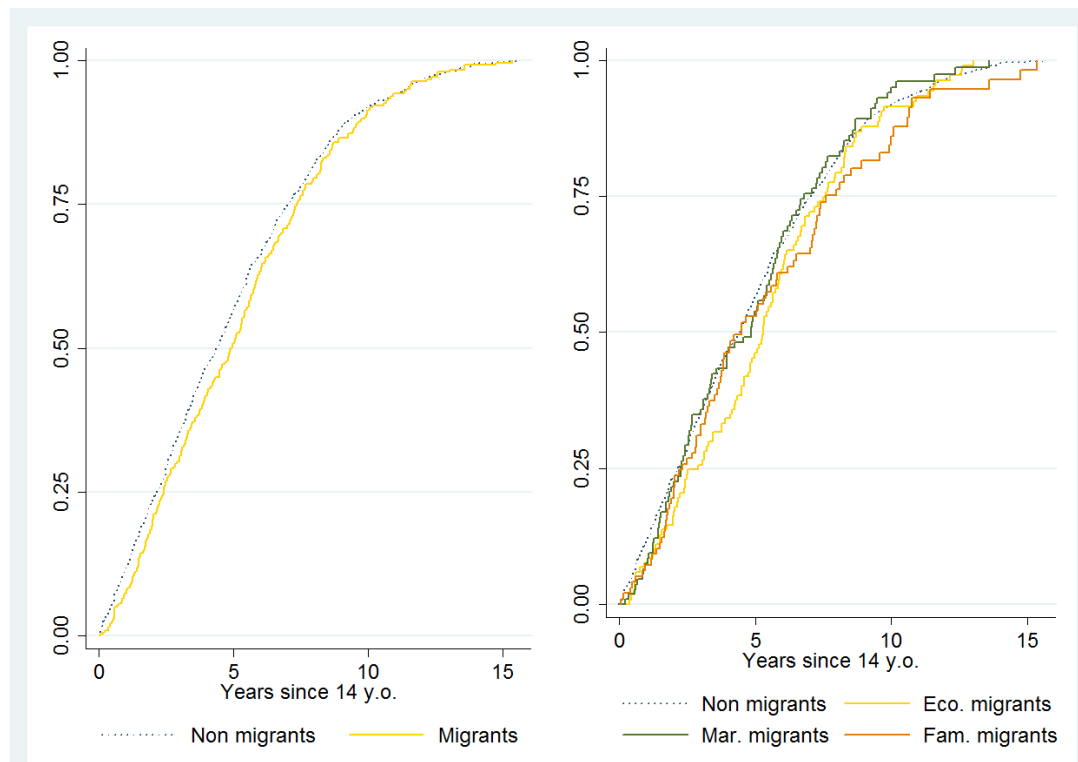

Figure 6: Kaplan-Meier failure function of transition length from school to a first job (condition 3)

Condition: Having ever attended school and not worked before end of schooling
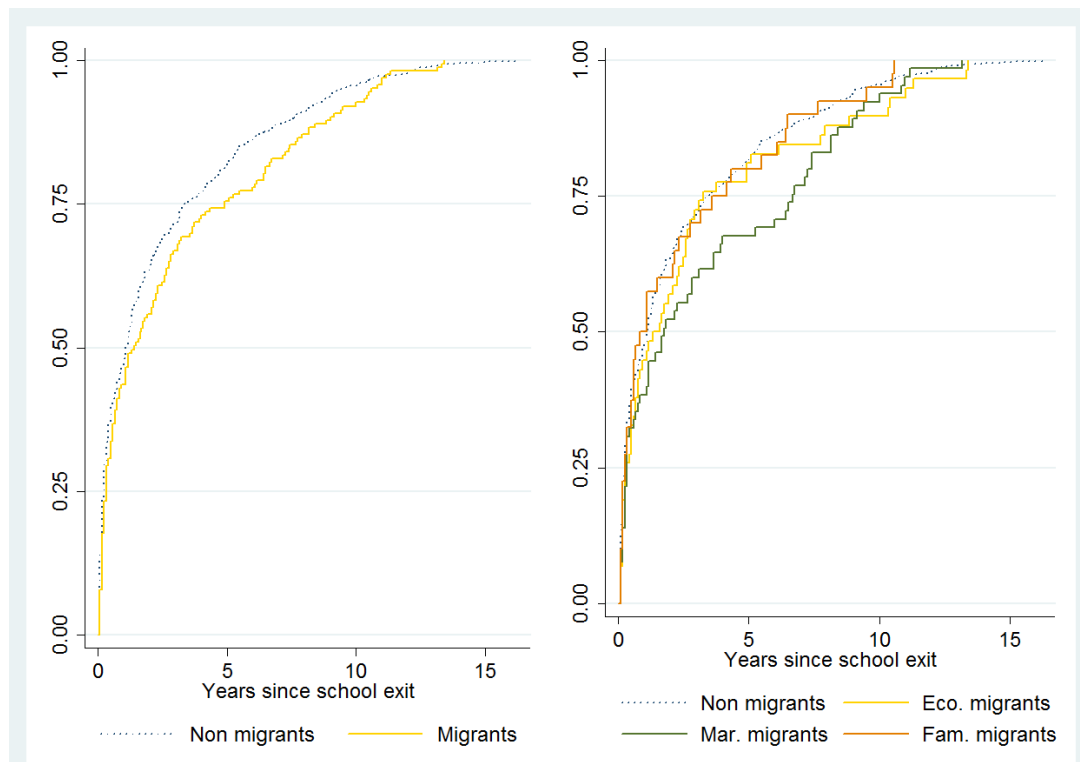


\section{Analysing the transition lengths gap}

Duration analysis is useful when one does not focus only on the duration of the event per se, but also on the likelihood that the event will end in the next period, given that it has lasted as long as it has. Cox proportional hazard models helps to go deeper in the analysis by studying the effect of risk factors on survival, i.e. the effect of some observable covariates on the likelihood to access to a first job before a given period of time.

\subsection{Cox-proportional hazard models}

\subsubsection{Model presentation}

The Kaplan-Meier estimates indicates whether there is a difference between the survival times of different groups, but it does not allow other explanatory variables to be taken into account. The most common approach to integrating meaningful covariates is the semi-parametric Cox survival model (Cox, 1972), that is applied here to provide an estimation of the average number of months taken to reach a first job.

Transition model expresses the hazard at time $\mathrm{t}$ for an individual with a given set of explanatory variable X. In this study, the hazard rate $\lambda(a)=f(a) / S(a)$ refers to the instantaneous prospect of leaving the never-employed state at age a, having never been employed up to that point. ${ }^{17}$ The higher is the hazard rate, the shorter will be the transition. As individual characteristics also influence the probability to find a job, the hazard rate should differ between members of the population according to a set of covariates that takes into account the level of education, the birth cohort, some background information and the familial status. A component $\theta$ is incorporated into the hazard function to disentangle the baseline hazard $\lambda_{0}(a)$ (common to all individuals) to the specific individual characteristics. A dummy of primary school attendance is included in this set of covariate and is considered as time-invariant as surveyed individuals are aged from 15 to 29 . Since some of them have still not finished their education at the time of the survey, the expected level of education is approximated by his same-sex parent's educational level. Area of origin and birth cohort (4-year span) that aims to control for some cohort effects are also included. The proportional hazard function is however violated by some characteristics of interest for which effect varies according to age. Being a migrant does not have the same effect (related to assimilation and the insertion into the labour market) for a 7 years old compared to a 23 years old, for example. A very young migrant is also more likely to be assimilated to residents than older migrants through an assimilation process and shared educational experiences. Being in an urban or rural area is also likely to change over time through migration. Some events, like getting married or having children, appear later in the life cycle but should be integrated as it might modify the job search behaviour. ${ }^{18}$ The Cox model is thus extended to include the set of time-varying covariates $Z_{i}(a)=Z_{i} g(a)$ that varies over age through the function $g(a)$. I fit the model to reflect that these covariates might have a declining effect over time. $g(a)$ is thus a logarithm function of age. Finally, I allow the baseline hazard to be different according to the area of origin (urban/rural) and sex by stratifying by these

\footnotetext{
${ }^{17}$ As time 0 corresponds to the date of birth, individual's survival time is represented by their age.

${ }^{18} \mathrm{~A}$ Schoenfeld residual test confirms that the mentioned variables should be considered as time-dependent.
} 
two variables. The predicted hazard for an individual $i$ is given by:

$$
\lambda_{r, s}(a)=\lambda_{0}(a) \exp \sum_{i=1}^{P}\left(\beta_{r, s} X_{i}\right)+g(a)\left[\sum_{i=1}^{P}\left(\gamma_{r, s} Z_{i}\right)\right]
$$

where $\lambda_{0}(a)$ is the baseline hazard, $X_{i}$ the time-invariant characteristics, $Z_{i}$ the time-varying characteristics, $r$ the stratification by area of origin and $s$ the stratification by sex. The semiparametric Cox model makes no assumption regarding the form of the hazard function that is estimated by maximum likelihood.

The first and the second transitions (conditions 1 and 2) have the same specification, only the time 0 changes (date of birth for the first transition, date when 14 years old is reached for the second). The school-to-work transition (condition 3) presents other features. First, the starting point is the date of school exit. As this starting point does not appear at the same age for all individuals, we add also age at exit in the set of covariates (one would expect the probability of an older school-leaver to have a higher risk ratio, both due to his age and the higher educational level completed). Second, the set of covariate changes: education level is directly estimated as all youth in this group has declared having finished their education.

\subsubsection{Results}

Table 3 presents exponentiated coefficients (hazard ratios) from the extended semi-parametric Cox proportional hazard model, with stratification by gender and area of origin when these variables are not added as covariates in the model. The hazard rates represent the conditional probability that a young enters a first job within a particular month, given that this has not occurred prior to this month. Note that hazard ratios have a different interpretation than a coefficient: they reflect relative risks, or in other terms the change in the log odds of the conditional probability of entering a first job, caused by a one-unit increase in the associated time-invariant covariate and by the logarithm of one unit of the associated time-varying variables. A hazard ratio larger than one indicates a faster transition, while a ratio lower than one suggests that the access to a first employ takes more time.

Columns (1), (4) and (7) estimate the hazard ratio with only the migration experience as explanatory variables and a stratification by sex and area of origin. Results with no control variables are similar to those found in Kaplan-Meier estimations: migrants have a lower hazard; therefore they spend a longer time in the never-employed state. Being a migrant reduces the risk of entering into employment by $4 \%$ to $11 \%$ according to the transitions. The difference in hazard ratio is however only significant for the first transition measure (condition 1). Interesting results emerge when adding the set of covariates and interaction terms. When controlling for relevant characteristics, migrant seems to enter faster than non-migrants to employment: the prospect of finding a job before the date of survey is $4 \%$ to $5 \%$ higher for migrants than for non-migrants (columns (2) and (5)). The school-to-work transition (condition 3) still shows no-significant impact of being a migrant on the duration of the never-employed state. Columns (3), (6) and (9) add interaction terms to take into account the heterogeneity of migrants. 
For easier interpretation, all specific hazard rates are recalculated according to the type of migrants (using interaction terms) and are presented in Annex table A3. Only the first transition measure is discussed here as the two others show no significant statistical differences in transition lengths between migrants and non-migrants. Transitions are found to be slightly faster for young men than women; migrant males find a first job at a younger age than migrant females in all areas considered. Results highlight different patterns according to the area of destination: migrating towards rural areas seems to hasten access to a first job while migrants located in urban areas face more difficulties. When disaggregating by types of migration, one can notice than the faster transition for migrants in respects to non-migrants is mainly driven by urban-to-rural migration and, to a lesser extent, by rural-to-rural migration (Annex table A3). A part of these types of migration is likely to be temporary migration of agricultural workforce, moving in response to labour demand. No significant difference can be observed between urban-to-urban migrants compared to urban non-migrants. By contrast, transition for migrants located in urban areas are longer; the risk for a non-migrant of staying in the state of never-employed before the time of survey is between $47 \%$ (for those originated from rural areas) to $46 \%$ (from urban areas) higher than for a non-migrant.

Regarding other covariates (Table 3), sex is a significant predictor of the hazard to be employed, consistent with the literature on unemployment duration. Being married increases the length of a transition but not in a significant way. Having children significantly hastens the school-to-work transition but has a differential impact depending on the sex: it accelerates the access to a first job for males and slows access for females. These results suggest a traditional distribution of tasks when it comes to parenting with men serving as the breadwinner while women take care of children and the household. One can notice that having attended school (whatever the indicators used) seems to increase the duration to a first job in comparison to not having education at all.

The migrant youth population is heterogeneous also in terms of reasons for migration. Estimations are re-performed in Annex table A4 on sub-samples of three-types of migrants: the first group gathers those who migrate for educational or employment purposes (159 observations). Young people in this group may have higher chance to be employed compared to other types of migrant, as they may have a stronger willingness to find a job. The second group clusters young women that migrate for marriage reasons (175 observations) should have access to social capital from their spouse, but may get bogged down in familial responsibilities. The third sub-population (176 observations) refers to youth that have migrated to follow their families, and may have benefited from the same childhood environment as non-migrants (though a discrimination effect might still exist). Regarding the first transition measure (condition 1), previous conclusion hold: the transition length is shorter for migrants than for non-migrants once relevant covariates are accounted for. The second and the third transition (conditions 2 and 3) present diverse results: while family-migrants enter a first job at an older age than non-migrants, the opposite pattern prevails for economic and marriage migrants. Whatever the destination, the school-to-work transition measure (condition 3) takes much more time for migrant females than non-migrant females, while the opposite effect prevails for young males. 
Table 3: Cox regressions on transitions to a first job

\begin{tabular}{|c|c|c|c|c|c|c|c|c|c|}
\hline & \multicolumn{3}{|c|}{ Transition 1} & \multicolumn{3}{|c|}{ Transition 2} & \multicolumn{3}{|c|}{ Transition 3} \\
\hline & $(1)$ & $(2)$ & $(3)$ & $(4)$ & $(5)$ & $(6)$ & $(7)$ & $(8)$ & (9) \\
\hline \multicolumn{10}{|c|}{ Time-varying covariates } \\
\hline \multirow[t]{2}{*}{ Migrant } & $0.892^{* *}$ & $1.043^{*}$ & $1.921^{* * *}$ & 0.958 & 1.049 & 1.175 & 0.916 & 0.968 & 0.912 \\
\hline & $(0.050)$ & $(0.024)$ & $(0.372)$ & $(0.064)$ & $(0.050)$ & $(0.136)$ & $(0.087)$ & $(0.057)$ & $(0.111)$ \\
\hline \multirow[t]{2}{*}{ Mig*rural origin } & & & $0.566^{* * *}$ & & & 0.893 & & & 1.017 \\
\hline & & & $(0.109)$ & & & $(0.096)$ & & & $(0.115)$ \\
\hline \multirow{2}{*}{$\begin{array}{l}\text { Mig*urban resi- } \\
\text { dence }\end{array}$} & & & $0.490^{* * *}$ & & & 0.841 & & & 1.064 \\
\hline & & & $(0.095)$ & & & $(0.093)$ & & & $(0.122)$ \\
\hline \multirow[t]{2}{*}{ Mig*male } & & & 1.021 & & & 1.094 & & & 1.041 \\
\hline & & & $(0.048)$ & & & $(0.106)$ & & & $(0.135)$ \\
\hline \multirow[t]{2}{*}{ Urban residence } & & 0.947 & $1.803^{* * *}$ & & 1.066 & $1.169^{* *}$ & & 1.057 & 1.029 \\
\hline & & $(0.032)$ & $(0.342)$ & & $(0.056)$ & $(0.089)$ & & $(0.056)$ & $(0.062)$ \\
\hline \multirow[t]{2}{*}{ With children } & & 0.995 & 0.992 & & 1.051 & 1.051 & & $0.901^{*}$ & $0.899^{*}$ \\
\hline & & $(0.026)$ & $(0.026)$ & & $(0.057)$ & $(0.057)$ & & $(0.056)$ & $(0.056)$ \\
\hline \multirow[t]{2}{*}{ Single } & & 0.990 & 0.984 & & 0.942 & 0.939 & & 0.983 & 0.978 \\
\hline & & $(0.026)$ & $(0.026)$ & & $(0.051)$ & $(0.051)$ & & $(0.060)$ & $(0.060)$ \\
\hline \multicolumn{10}{|c|}{ Time-invariant covariates } \\
\hline \multirow[t]{2}{*}{ Male } & & $1.161^{* *}$ & $* 1.147 * *$ & & $1.167^{* *}$ & $1.136^{*}$ & & $1.145^{*}$ & $1.149^{*}$ \\
\hline & & $(0.062)$ & $(0.066)$ & & $(0.073)$ & $(0.074)$ & & $(0.088)$ & $(0.088)$ \\
\hline \multirow[t]{2}{*}{ Rural origin } & & 1.086 & $6.230^{* * *}$ & & $1.202^{* *}$ & $1.377^{* * *}$ & & $1.152^{*}$ & 1.147 \\
\hline & & $(0.102)$ & $(3.324)$ & & $(0.103)$ & $(0.165)$ & & $(0.097)$ & $(0.097)$ \\
\hline \multirow[t]{2}{*}{ Parents-primary } & & $0.856^{* *}$ & $* 0.859^{* *}$ & & 0.903 & 0.908 & & & \\
\hline & & $(0.051)$ & $(0.051)$ & & $(0.069)$ & $(0.070)$ & & & \\
\hline \multirow{3}{*}{$\begin{array}{l}\text { Parents- } \\
\text { secondary }\end{array}$} & & $0.757^{* *}$ & $* 0.775^{* * *}$ & & $0.807^{*}$ & $0.819^{*}$ & & & \\
\hline & & & & & & & & & \\
\hline & & $(0.075)$ & $(0.076)$ & & $(0.095)$ & $(0.096)$ & & & \\
\hline \multirow[t]{2}{*}{ Parents-higher } & & $0.777^{*}$ & $0.795^{*}$ & & 0.894 & 0.909 & & & \\
\hline & & $(0.104)$ & $(0.107)$ & & $(0.135)$ & $(0.137)$ & & & \\
\hline \multirow[t]{2}{*}{ Primary level } & & $1.612^{* *}$ & $* 1.600 * * *$ & & $1.537^{* * *}$ & ${ }^{k} 1.526^{* * *}$ & & 1.281 & $1.310^{*}$ \\
\hline & & $(0.086)$ & $(0.085)$ & & $(0.100)$ & $(0.099)$ & & $(0.201)$ & $(0.209)$ \\
\hline \multirow[t]{2}{*}{ Secondary level } & & & & & & & & 1.077 & 1.098 \\
\hline & & & & & & & & $(0.168)$ & $(0.174)$ \\
\hline Higher level & & & & & & & & 0.987 & 1.008 \\
\hline & & & & & & & & $(0.157)$ & $(0.162)$ \\
\hline Age school exit & & & & & & & & $1.276^{* * *}$ & k $1.277^{* * *}$ \\
\hline & & & & & & & & $(0.019)$ & $(0.019)$ \\
\hline Control for cohort & No & Yes & Yes & $\mathrm{No}$ & Yes & Yes & No & Yes & Yes \\
\hline Stratification & Yes & No & No & Yes & No & No & Yes & No & No \\
\hline Observations & 2,208 & 1,914 & 1,914 & 1,530 & 1,305 & 1,305 & 744 & 744 & 744 \\
\hline
\end{tabular}

Stratified by sex and area of origin. Note: migrant is considered as time-invariant in model (1), (3) and (5) and as time-varying observable in models (2), (4) and (6). Variables in tvc equation interacted with $\ln \left(\_t\right)$. Transition 1: from date of birth to first job. Transition 2: from 14 years old to first job. Transition 3: from end of school to first job. 


\subsection{Decomposition in duration model}

\subsubsection{Difference in structure and endowments}

This paper does not address the presence of unobserved heterogeneity due to the selection into migration that potentially leads to bias in the comparison of $\lambda_{r, s}(a)$. Migrants may have specific characteristics highly valued in the labour market, which can accelerate their access to a first job. One specific example is the use of informal job-search channels (migrant network) to obtain a first job, which is likely to be a non-random characteristic highly correlated with both migration status and labour market outcomes. Others characteristics like attitude toward work or discrimination from the local population can also modify the observed duration through a difference in returns of each covariate.

The proportion of these unexplained factors can be estimated through decomposition methods. Oaxaca-Blinder (Oaxaca, 1973; Blinder, 1973) decomposition techniques have been extensively used in the labour economics literature to decompose some gaps in linear models (generally wage differentials) into an explained/endowment part and an unexplained/discrimination one (see Fortin et al. (2011), for a comprehensive literature review). ${ }^{19}$

Many studies have attempted to adapt the regression-based decomposition when the relationship between the outcome studied and the covariates is not linear. The extension of the detailed decomposition to non-linear models is not straightforward and introduces a number of econometric challenges for estimating it without strong assumptions. ${ }^{20}$ First, results are sensitive to the order in which variables enter into decomposition (the so-called path-dependency). Second, specific properties to the decomposition cannot be applied (notably the additive linearity and the mean conditional independence assumptions).

The Yun decomposition method (Yun, 2004) is an approximation of the Oaxaca-Blinder decomposition for non-linear models that handle path-dependency. This method uses counterfactual scenario by comparing the sample mean of the estimated function for migrants and locals. ${ }^{21}$ Let $^{2}$ us denote the subscript $m$ for migrants and $r$ for residents, while $F\left(X_{m} \beta_{m}\right)$ and $F\left(X_{r} \beta_{r}\right)$ respectively refer to the cumulated hazard function for migrants and residents. The mean difference in cumulated hazard between $m$ and $r$ can be expressed as follows:

\footnotetext{
${ }^{19}$ The original Oaxaca-Blinder decomposition is estimated by first obtaining the parameters $\beta$ from ordinary least square (OLS) regression for each group (here migrants $m$ and resident $r$ ), and second by defining a counterfactual situation, that is to say by determining the value of the outcome $y$ that one group would have if it had the same values of covariates than the other group. The difference in sample mean $\bar{y}_{m}-\bar{y}_{r}$ is then decomposed into an unexplained -or structure- effect and an explained component -or composition or endowment- effect. There is discrimination when the structure effect is non-zero while the two groups have the same mean in observables.

${ }^{20}$ The aggregate decomposition using counterfactual regression is possible whatever the shape of the distributional statistics

${ }^{21}$ Due to the Jensen inequality and the non-linear nature of the outcome, even if the two groups have identical means in observables, the decomposition does not result only in a structure effect. A remainder term is confounded with the unexplained effect, leading to an approximation of the discrimination extent (Bazen \& Joutard, 2013).
} 
The first term of the equation refers to the composition (explained) effect, that is to say, the part of the differential attributable to differences in characteristics. It reflects the counterfactual comparison of the gap in transition lengths from the migrant perspective, or in others words, the difference in outcome if migrants were given residents' distribution of covariates. The second term is the part of the differential attributable to differences in coefficients. This (unexplained) effect reflects the residents' perspectives, which are the expected difference in residents' transition length if there were experienced migrants' behavioural responses to covariates. This unexplained factor confound differences in returns of unobservable characteristics and unobserved skills (such as differences in search frictions, reservation wages and level of productivity) that has led to selection into migration and are correlated with labour market outcomes.

The detailed decomposition in non-linear models, aiming to represent the specific contribution of each covariate to both the composition and structure effect, faces the problem of path-dependence. Yun (2004) uses weights derived from a first-order Taylor linearisation of equation (3) around $X_{r} \beta_{r}$ and $X_{m} \beta_{m}$. The detailed decomposition can be re-written as:

$\overline{F\left(X_{m} \beta_{m}\right)}-\overline{F\left(X_{r} \beta_{r}\right)}=\sum_{k=1}^{K} W_{X k}\left[\overline{F\left(X_{m} \beta_{m}\right)}-\overline{F\left(X_{r} \beta_{m}\right)}\right]+\sum_{k=1}^{K} W_{\beta k}\left[\overline{F\left(X_{r} \beta_{m}\right)}-\overline{F\left(X_{r} \beta_{r}\right)}\right]$

where the weight funtions $W_{\beta k}=\frac{\bar{X}_{k}^{M}\left(\hat{\beta}_{k}^{M}-\hat{\beta}_{k}^{R}\right)}{\sum_{k=1}^{K} \bar{x}_{k}^{M}\left(\hat{\beta}_{k}^{M}-\hat{\beta}_{k}^{R}\right)}$ is the coefficient weights reflecting the relative contribution of each covariate (based on the magnitude of the difference in the size of the effect) weighted by the mean value of the covariate in the resident group. The composition weights $W_{x k}=\frac{\bar{\beta}_{k}^{M}\left(\bar{x}_{k}^{M}-\bar{x}_{k}^{R}\right)}{\sum_{k=1}^{K} \bar{\beta}_{k}^{M}\left(\bar{x}_{k}^{M}-\bar{x}_{k}^{R}\right)}$ reflect the relative contribution of each covariate based on the magnitude of the difference in the mean value of the covariate, weighted by the effect of the covariate in the migrant group. We apply this simple and path-independent method to disentangle the sources of the migration and gender gaps in mean transition duration.

\subsubsection{Results}

While literature tends to focus on the specific role of education and family background in explaining any difference in labour market performance, Table 4 shows that most of the raw gap in measure 1 and measure 3 is due to the unexplained component. The unexplained effect quantifies the change in migrants' hazard when applying the non-migrants' coefficients to the migrants' characteristics (difference in structure). The unexplained component has a complex interpretation as it reflects one or more factors, including omitted characteristics, unobservable characteristics, differences in behaviour or preferences, or discrimination.

One striking results is that the unexplained part for the first transition is almost exclusively driven by the fact of being originated from (for migrants) or having ever lived in (for non-migrants) 
a rural area. The unobservable effect of this variable disappears when focusing on the non-child labourers (condition 2), suggesting that the results might be driven by difference in preference regarding child labour in rural areas. When the young person has never been a child labourer (transition 2), only the difference in return to gender (through some discrimination effect or preference for family rather than work) influences the unexplained part of the gap between migrants and non-migrants transition lengths. However, the raw gap in the second transition measure (condition 2 ) is due to the explained component. This component reflects the main decrease in migrants' hazard if they had the same characteristics than non-migrants (difference in endowments), or in other terms what the migrant gap in transition length would be if migrants and non-migrants would have the same characteristics: transition length would be higher for migrants. When we look at the detailed decomposition, we see that the gap is mainly due to differences in age cohorts and levels of education between migrants and non-migrants. The same observable factors explain also (in similar magnitudes) the explained component of the first transition.

Table 4: Overall and detailed decomposition

\begin{tabular}{l|cc|cc|cc}
\hline & \multicolumn{2}{|c}{ Transition condition 1 } & \multicolumn{2}{c}{ Transition condition 2 } & \multicolumn{2}{c}{ Transition condition 3 } \\
\hline & Explained & Unexplained & Explained & Unexplained & Explained & Unexplained \\
\hline \hline Overall & 0.145 & 1.218 & 0.135 & 0.066 & 0.048 & 0.257 \\
\hline Parents-primary & 0.000 & 0.002 & 0.000 & -0.037 & 0.000 & -0.204 \\
Parents-secondary & 0.001 & 0.000 & 0.001 & 0.000 & 0.000 & -0.003 \\
Parents-higher & 0.000 & 0.000 & 0.000 & -0.001 & 0.000 & -0.001 \\
Primary level & 0.021 & 0.004 & 0.021 & -0.010 & 0.023 & -0.004 \\
Rural origin & 0.001 & 1.292 & 0.001 & 0.000 & 0.000 & -0.004 \\
Male & 0.010 & 0.010 & 0.010 & -0.067 & 0.131 & -0.381 \\
Have children & 0.000 & 0.001 & 0.000 & -0.011 & 0.009 & -0.026 \\
Single & 0.001 & 0.001 & 0.002 & -0.004 & 0.001 & 0.000 \\
Urban residence & 0.001 & 0.021 & 0.000 & -0.003 & 0.010 & -0.007 \\
15-19 y.o. & 0.003 & 0.000 & 0.002 & 0.000 & 0.005 & -0.004 \\
20-24 y.o. & 0.034 & 0.000 & 0.039 & -0.012 & 0.022 & -0.002 \\
25-29 y.o. & 0.007 & 0.001 & 0.006 & -0.010 & 0.005 & 0.000 \\
\hline
\end{tabular}

The school-to-work transition (condition 3) follows different patterns in explaining the migrantnon-migrants transitions length differentials. Regarding the explained component, gender has a leading role, even though access to education, age cohort and having children have also some influence. However, the raw gap in school-to-work transition is mainly driven by the unexplained part, and more precisely by difference in returns to gender and education. 


\section{Conclusion}

This paper aimed to analyse if there is some differential in first job transition between young people that have experienced migration and non-migrants. To this purpose, several transition lengths of access to a first job are estimated to approximate the difficulties a young person can experience in the labour market. Estimations from a Cox-proportional hazard models revealed that migrants attain a first job at a younger age than non-migrants (condition 1) but there is no significant difference in transition lengths for the measurement group of non-child labourers (condition 2 ). The school-to-work transition (condition 3) shows that the transition is shorter for migrants than for non-migrants, but still not in a significant way.

Further results highlight the need to take into account migrants' heterogeneity: findings differ widely according to the area of origin and destination: migration can accelerate the transition to a first job process only in urban areas. Urban-to-rural migrants are worse-off as they have 92 per cent lower chance to find a first job than rural non-migrants, potentially due to a mismatch in their qualifications. There are no sharp observed differences between young men and women. Results differ also according to the reasons for migration. In particular, while family-migrants enter a first job at an older age than non-migrants, the opposite patterns prevail for economic and marriage migrants. Whatever the destination, the school-to-work transition takes much more time for migrant than non-migrant females, while the opposite prevails for young males.

Any generalization toward discrimination according to sex, the area of origin and/or residence is however misleading as the distribution of age, education and personality is different between migrants and non-migrants. A Yun's (Yun, 2004) decomposition was performed to distinguish if the differential in transition is due to a gap in observables or relied more on unobservable effects. Here again, results differs according to the transition measure studied: under condition 1, the transition gap in duration is mainly driven by unobservable factors, related to rural origin, while under condition 2 (for non-child labourers), the gap is explained by observable level of education and age cohort. It suggests a differential role regarding child labour preference among migrants and non-migrants. Differences in transition duration from the end of school to a first job are led by explained and unexplained effects of gender and education.

\section{References}

Adsera, Alicia, \& Chiswick, Barry R. 2006. Divergent patterns in immigrant earnings across European destinations. Immigration and the transformation of Europe, 85-110.

Arrow, Kenneth Joseph, et al. 1973. The theory of discrimination.

Arulampalam, Wiji. 2001. Is unemployment really scarring? Effects of unemployment experiences on wages. The Economic Journal, 111(475), 585-606.

Basu, Sukanya. 2015. Intermarriage And The Labor Market Outcomes Of Asian Women. Economic Inquiry, 53(4), 1718-1734. 
Bazen, Stephen, \& Joutard, Xavier. 2013. The Taylor decomposition: A unified generalization of the Oaxaca method to nonlinear models.

Becker, Gary S. 1962. Investment in human capital: A theoretical analysis. The journal of political economy, 9-49.

Beegle, Kathleen, \& Poulin, Michelle. 2013. Migration and the transition to adulthood in contemporary Malawi. The ANNALS of the American Academy of Political and Social Science, 648(1), $38-51$.

Bentolila, Samuel, Michelacci, Claudio, \& Suarez, Javier. 2010. Social contacts and occupational choice. Economica, $\mathbf{7 7}(305), 20-45$.

Blinder, Alan S. 1973. Wage discrimination: reduced form and structural estimates. Journal of Human resources, 436-455.

Bonin, Holger, Constant, Amelie, Tatsiramos, Konstantinos, \& Zimmermann, Klaus F. 2009. Native-migrant differences in risk attitudes. Applied Economics Letters, 16(15), 1581-1586.

Borjas, George J. 1985. Assimilation, changes in cohort quality, and the earnings of immigrants. Journal of labor Economics, 463-489.

Borjas, George J. 1987. Self-selection and the earnings of immigrants.

Cain, Glen George, et al. 1986. The economic analysis of labor market discrimination: A survey.

Cassarino, Jean-Pierre. 2004. Theorising return migration: The conceptual approach to return migrants revisited. International Journal on Multicultural Societies (IJMS), 6(2), 253-279.

Chiswick, Barry R. 1978. The effect of Americanization on the earnings of foreign-born men. The journal of political economy, 897-921.

Chiswick, Barry R. 1999. Are immigrants favorably self-selected? The American economic review, 89(2), 181-185.

Chiswick, Barry R, \& Miller, Paul W. 2012. Negative and positive assimilation, skill transferability, and linguistic distance. Journal of Human Capital, 6(1), 35-55.

Christiaensen, Luc, Weerdt, Joachim, \& Todo, Yasuyuki. 2013. Urbanization and poverty reduction: the role of rural diversification and secondary towns1. Agricultural Economics, 44(4-5), 435-447.

Clark, Ken, \& Drinkwater, Stephen. 2008. The labour-market performance of recent migrants. Oxford Review of Economic Policy, 24(3), 495-516.

Cox, David R. 1972. Regression models and life tables (with discussion). Journal of the Royal Statistical Society, 34, 187-220.

De Brauw, Alan, Mueller, Valerie, \& Lee, Hak Lim. 2014. The role of rural-urban migration in the structural transformation of Sub-Saharan Africa. World Development, 63, 33-42. 
De Vreyer, Philippe, Gubert, Flore, \& Robilliard, Anne-Sophie. 2010. Are there returns to migration experience? An empirical analysis using data on return migrants and non-migrants in West Africa. Annals of Economics and Statistics/Annales dâÉconomie et de Statistique, 307-328.

Démurger, Sylvie, \& Xu, Hui. 2011. Return migrants: The rise of new entrepreneurs in rural China. World Development, 39(10), 1847-1861.

Dustmann, Christian, Glitz, Albrecht, \& Frattini, Tommaso. 2008. The labour market impact of immigration. Oxford Review of Economic Policy, 24(3), 477-494.

Fields, Gary S. 1975. Rural-urban migration, urban unemployment and underemployment, and job-search activity in LDCs. Journal of development economics, 2(2), 165-187.

Fortin, Nicole, Lemieux, Thomas, \& Firpo, Sergio. 2011. Decomposition methods in economics. Handbook of labor economics, 4, 1-102.

Harris, John R, \& Todaro, Michael P. 1970. Migration, unemployment and development: a twosector analysis. The American economic review, 60(1), 126-142.

IOM. 2015. Migration in Uganda - a rapid country profile 2013. International Organization for Migration.

Katz, Eliakim, \& Stark, Oded. 1986. Labor migration and risk aversion in less developed countries. Journal of labor Economics, 134-149.

Kerr, Sari Pekkala, \& Kerr, William R. 2011. Economic impacts of immigration: A survey. Tech. rept. National Bureau of Economic Research.

Knight, John, \& Yueh, Linda. 2004. Job mobility of residents and migrants in urban China. Journal of Comparative Economics, 32(4), 637-660.

Kudo, Yuya. 2015. Female migration for marriage: Implications from the land reform in rural Tanzania. World Development, 65, 41-61.

Marchetta, Francesca. 2012. Return migration and the survival of entrepreneurial activities in Egypt. World Development, 40(10), 1999-2013.

McMillan, Margaret S, \& Harttgen, Kenneth. 2014. What is driving the'African Growth Miracle'? Tech. rept. National Bureau of Economic Research.

Musonda, Flora Mndeme. 2006. Migration Legislation in East Africa. International Labour Office.

Oaxaca, Ronald. 1973. Male-female wage differentials in urban labor markets. International economic review, 693-709.

Phelps, Edmund S. 1972. The statistical theory of racism and sexism. The american economic review, 62(4), 659-661.

Pissarides, Christopher A. 2000. Equilibrium unemployment theory. MIT press.

Rosenzweig, Mark R, \& Stark, Oded. 1989. Consumption smoothing, migration, and marriage: Evidence from rural India. The Journal of Political Economy, 905-926. 
Roy, Andrew Donald. 1951. Some thoughts on the distribution of earnings. Oxford economic papers, 3(2), 135-146.

Ssennono, V.F, Guarcello, L., Rosati, F., \& Breglia, G. 2008. Understanding children's work in Uganda.

Thomas, Kevin JA. 2008. Return migration in Africa and the relationship between educational attainment and labor market success: Evidence from Uganda. International Migration Review, 42(3), 652-674.

Todaro, Michael P. 1969. A model of labor migration and urban unemployment in less developed countries. The American economic review, 59(1), 138-148.

UBOS. 2012. 2012 Statistical Abstract. Tech. rept. Uganda Bureau of Statistics.

Udall, Alan T, \& Sinclair, Stuart. 1982. The "luxury unemployment" hypothesis: A review of recent evidence. World Development, 10(1), 49-62.

UNHCR. 2011. Baseline Study: Documenting Knowledge, Attitudes and Practices of Refugees and the Status of Family Planning Services in UNHCR's Operations in Nakivale Refugee Settlement, Uganda. Women's Refugee Commission, New York.

Yang, Quanhe, \& Guo, Fei. 1996. Occupational attainments of rural to urban temporary economic migrants in China, 1985-1990. International Migration Review, 771-787.

Yun, Myeong-Su. 2004. Decomposing differences in the first moment. Economics letters, 82(2), $275-280$. 


\section{Annex A. Kaplan-Meier estimates - Further results}

Table A1: Kaplan-Meier failure function - Transition to a first job accroding to reason for migration

\begin{tabular}{l|c|cccc}
\hline & Non-migrants & All types & $\begin{array}{c}\text { Migrants } \\
\text { Economic migrant }\end{array}$ & Marriage & Family migrant \\
\hline \hline Years since T0 & & & & & \\
5 & 0.000 & 0.000 & 0.000 & 0.000 & 0.000 \\
10 & 0.1372 & 0.0747 & 0.0355 & 0.0833 & 0.1067 \\
14 & 0.3188 & 0.2431 & 0.1633 & 0.3077 & 0.252 \\
20 & 0.7708 & 0.7232 & 0.6789 & 0.7756 & 0.7074 \\
25 & 0.9604 & 0.9561 & 0.9451 & 0.9728 & 0.9478 \\
29 & 0.9981 & 0.9969 & 1.000 & 1.000 & 0.987 \\
\hline Log-rank test & & & & & \\
chi2(1) & & 8.5 & 8.71 & 0.00 & 5.29 \\
Pr2 & & 0.0035 & 0.0032 & 0.9806 & 0.021 \\
\hline
\end{tabular}

Table A2: Kaplan-Meier failure function - Transition to a first job according to origin and destination areas

\begin{tabular}{|c|c|c|c|c|c|c|}
\hline \multirow[b]{3}{*}{ Years since T0 } & \multicolumn{3}{|c|}{ Destination: Urban areas } & \multicolumn{3}{|c|}{ Destination: Rural areas } \\
\hline & \multirow{2}{*}{ Non-migrants } & \multicolumn{2}{|c|}{ Migrants } & \multirow{2}{*}{ Non-migrants } & \multicolumn{2}{|c|}{ Migrants } \\
\hline & & From urban & From rural & & From urban & From rural \\
\hline 5 & 0.000 & 0.000 & 0.000 & 0.000 & 0.000 & 0.000 \\
\hline 10 & 0.0643 & 0.0149 & 0.0297 & 0.1597 & 0.1218 & 0.0714 \\
\hline 14 & 0.1833 & 0.1194 & 0.1688 & 0.3604 & 0.335 & 0.1968 \\
\hline 20 & 0.6719 & 0.5877 & 0.6457 & 0.801 & 0.8402 & 0.644 \\
\hline 25 & 0.9372 & 0.9383 & 0.912 & 0.9674 & 0.9893 & 0.9485 \\
\hline 29 & 1.000 & 1.000 & 1.000 & 0.9975 & 1.000 & 0.9742 \\
\hline $\begin{array}{l}\text { Log-rank test } \\
\text { chi2(1) }\end{array}$ & & 1.95 & 0.21 & & 0.25 & 7 \\
\hline Pr2 & & 0.1625 & 0.6429 & & 0.6181 & 0.0081 \\
\hline
\end{tabular}


Table A3: Migrants heterogeneity - Cox PH estimations (hazard ratio)

\begin{tabular}{|c|c|c|c|c|c|c|c|c|}
\hline Condition1 & $\begin{array}{l}0.533^{* * *} \\
(0.102)\end{array}$ & $\begin{array}{l}0.544^{* * *} \\
(0.107)\end{array}$ & $\begin{array}{l}1.087^{* *} \\
(0.036)\end{array}$ & $\begin{array}{l}1.109^{* *} \\
(0.049)\end{array}$ & $\begin{array}{l}1.921^{\text {*** }} \\
(0.372)\end{array}$ & $\begin{array}{l}1.962^{* * *} \\
(0.377)\end{array}$ & $\begin{array}{l}0.942 \\
(0.048)\end{array}$ & $\begin{array}{l}0.962 \\
(0.052)\end{array}$ \\
\hline Condition2 & $\begin{array}{l}0.882 \\
(0.089)\end{array}$ & $\begin{array}{l}0.966 \\
(0.122)\end{array}$ & $\begin{array}{l}1.049 \\
(0.076)\end{array}$ & $\begin{array}{l}1.148 \\
(0.113)\end{array}$ & $\begin{array}{l}1.175 \\
(0.136)\end{array}$ & $\begin{array}{l}1.286^{* *} \\
(0.143)\end{array}$ & $\begin{array}{l}0.988 \\
(0.097)\end{array}$ & $\begin{array}{l}1.081 \\
(0.108)\end{array}$ \\
\hline Condition3 & $\begin{array}{l}1.044 \\
(0.103)\end{array}$ & $\begin{array}{l}1.033 \\
(0.158)\end{array}$ & $\begin{array}{l}0.933 \\
(0.080)\end{array}$ & $\begin{array}{l}0.923 \\
(0.128)\end{array}$ & $\begin{array}{l}0.912 \\
(0.111)\end{array}$ & $\begin{array}{l}0.903 \\
(0.122)\end{array}$ & $\begin{array}{l}1.020 \\
(0.131)\end{array}$ & $\begin{array}{l}1.010 \\
(0.149)\end{array}$ \\
\hline $\begin{array}{l}\text { Sex } \\
\text { Residence } \\
\text { Origin }\end{array}$ & $\begin{array}{l}\text { Female } \\
\text { Urban } \\
\text { Rural }\end{array}$ & $\begin{array}{l}\text { Male } \\
\text { Urban } \\
\text { Rural }\end{array}$ & $\begin{array}{l}\text { Female } \\
\text { Rural } \\
\text { Rural }\end{array}$ & $\begin{array}{l}\text { Male } \\
\text { Rural } \\
\text { Rural }\end{array}$ & $\begin{array}{l}\text { Female } \\
\text { Rural } \\
\text { Urban }\end{array}$ & $\begin{array}{l}\text { Male } \\
\text { Rural } \\
\text { Urban }\end{array}$ & $\begin{array}{l}\text { Female } \\
\text { Urban } \\
\text { Urban }\end{array}$ & $\begin{array}{l}\text { Male } \\
\text { Urban } \\
\text { Urban }\end{array}$ \\
\hline
\end{tabular}


Table A4: Cox regressions - Transitions to a first job by reasons for migration

\begin{tabular}{|c|c|c|c|c|c|c|c|c|c|}
\hline & \multicolumn{3}{|c|}{ Transition 1} & \multicolumn{3}{|c|}{ Transition 2} & \multicolumn{3}{|c|}{ Transition 3} \\
\hline & $(1)$ & $(2)$ & $(3)$ & $(4)$ & $(5)$ & (6) & $(7)$ & (8) & $(9)$ \\
\hline & \multicolumn{9}{|c|}{ Economic migrants } \\
\hline \multirow[t]{2}{*}{ Migrant } & $0.807^{* *}$ & 1.036 & $1.951^{* * *}$ & 0.936 & 1.122 & $1.382^{*}$ & 0.889 & 0.961 & 0.850 \\
\hline & $(0.072)$ & $(0.041)$ & $(0.427)$ & $(0.093)$ & $(0.085)$ & $(0.239)$ & $(0.125)$ & $(0.084)$ & $(0.167)$ \\
\hline \multirow[t]{2}{*}{ mig*rural origin } & & & $0.585^{* *}$ & & & 1.035 & & & 1.019 \\
\hline & & & $(0.126)$ & & & $(0.167)$ & & & $(0.182)$ \\
\hline \multirow{2}{*}{$\begin{array}{l}\text { mig*urban resi- }^{*} \text { dence }\end{array}$} & & & $0.469^{* * *}$ & & & $0.723^{*}$ & & & 1.121 \\
\hline & & & $(0.100)$ & & & $(0.124)$ & & & $(0.246)$ \\
\hline \multirow[t]{2}{*}{ mig*male } & & & 1.050 & & & 0.971 & & & 1.111 \\
\hline & & & $(0.077)$ & & & $(0.139)$ & & & $(0.213)$ \\
\hline \multirow[t]{2}{*}{ Observations } & 1,926 & 1,676 & 1,676 & 1,329 & 1,140 & 1,140 & 729 & 729 & 729 \\
\hline & \multicolumn{9}{|c|}{ Marriage migrants } \\
\hline \multirow[t]{2}{*}{ Migrant } & 1.002 & $1.112^{* *}$ & $* 2.041^{* * *}$ & 1.033 & 1.085 & $1.477^{* *}$ & 0.861 & 0.987 & 1.049 \\
\hline & $(0.090)$ & $(0.041)$ & $(0.448)$ & $(0.112)$ & $(0.085)$ & $(0.262)$ & $(0.117)$ & $(0.082)$ & $(0.214)$ \\
\hline \multirow{2}{*}{ mig*rural origin } & & & $0.562^{* * *}$ & & & 0.795 & & & 0.941 \\
\hline & & & $(0.124)$ & & & $(0.149)$ & & & $(0.199)$ \\
\hline \multirow{2}{*}{$\begin{array}{l}\text { mig*urban resi- }^{*} \\
\text { dence }\end{array}$} & & & $0.485^{* * *}$ & & & $0.678^{* *}$ & & & 0.958 \\
\hline & & & $(0.106)$ & & & $(0.119)$ & & & $(0.186)$ \\
\hline \multirow[t]{2}{*}{ mig*male } & & & 1.021 & & & $8,090.202^{*}$ & $* *$ & & 1.000 \\
\hline & & & $(0.395)$ & & & $(22,713.50$ & & & $(0.000)$ \\
\hline \multirow[t]{2}{*}{ Observations } & 1,939 & 1,689 & 1,689 & 1,320 & 1,135 & 1,135 & 737 & 737 & 737 \\
\hline & \multicolumn{9}{|c|}{ Family migrants } \\
\hline \multirow[t]{2}{*}{ migrant } & 0.882 & 0.983 & $1.696^{* *}$ & 0.893 & 0.951 & 0.757 & 1.010 & 0.992 & 0.816 \\
\hline & $(0.086)$ & $(0.037)$ & $(0.371)$ & $(0.103)$ & $(0.072)$ & $(0.152)$ & $(0.170)$ & $(0.105)$ & $(0.223)$ \\
\hline \multirow[t]{2}{*}{ mig*rural origin } & & & $0.567^{* * *}$ & & & 1.037 & & & 1.113 \\
\hline & & & $(0.121)$ & & & $(0.191)$ & & & $(0.283)$ \\
\hline \multirow{2}{*}{$\begin{array}{l}\text { mig* }^{*} \text { rban resi- } \\
\text { dence }\end{array}$} & & & $0.526^{* * *}$ & & & 1.144 & & & 1.525 \\
\hline & & & $(0.116)$ & & & $(0.221)$ & & & $(0.427)$ \\
\hline \multirow[t]{2}{*}{ mig*male } & & & 1.095 & & & $1.440^{* *}$ & & & 1.079 \\
\hline & & & $(0.083)$ & & & $(0.227)$ & & & $(0.253)$ \\
\hline Observations & 1,915 & 1,677 & 1,677 & 1,307 & 1,132 & 1,132 & 710 & 710 & 710 \\
\hline
\end{tabular}

